\title{
On the Development and Present Situation of Medical Education in China
}

\author{
Haidong Zhu' ${ }^{1, a}$, Jialin Gao ${ }^{1, b, *}$ \\ ${ }^{1}$ Department of Urology, The First Hospital of Jilin University, Jilin, China \\ a867350670@qq.com, bgj@jlu.edu.cn
}

\begin{abstract}
Under the background of economic globalization, carrying out medical education is of great significance for improving the level of medical education of the country. The development of medical education in China has entered a new stage of development. How to realize the integration of medical education with international standards is a question that is worth thinking. Of course, it is a long process to realize the internationalization of medical education, which requires constant persistence and improvement. While drawing on international advanced experience, we should also explore the form of medical education in China and take the international road that is most suitable for the development of medical education in China.
\end{abstract}

Keywords: Medical education; Development.

Medical education refers to education activity that aims, plans and organizes the cultivation of medical and health talents according to the needs of the society. It generally refers to the medical college education at the university level. China's medical education begins in the Northern and Southern Dynasties and has a history of more than 1,500 years. After the founding of the People's Republic of China, education structure in the form of primary, secondary, higher, postgraduate and advanced study education has been basically established, forming a complete and multi-level medical education system (See The list of Chinese medical education forms and levels). While developing modern medical education, it has laid the foundation for Chinese medicine education and developed medical education in border areas and minority areas. Medical education then forms a corresponding curriculum system, including: (1) Public basic courses, including humanities and social sciences, providing cultural and moral education to students; (2) General basic courses, including biology, physics, chemistry, mathematics and other natural science courses, laying the foundation for medical study; (3) Basic medical courses, disciplines on the normal and abnormal morphological structure and function of the human body, and basic theoretical knowledge of treatment and prevention, laying the foundation for clinical medicine study; (4) Medical clinical course. Its teaching arrangement is based on discipline as the unit and follows the principle of gradual progress. From the general to the medical and from the basic to the clinical, the whole teaching process is divided into three stages: general medicine, basic medicine and clinical medicine. The first is the pre-medical period, setting up public basic courses and general basic courses, and students basically do not touch medicine. Some countries put this stage of teaching as a medical preparatory course in a comprehensive university; China, Japan, the Soviet Union, and Eastern European countries study in the first 1-2 years after entering the medical school. The second is the pre-clinical period. With the establishment of basic medical courses, medical students begin to learn the basic theoretical knowledge and skills of medicine, but do not touch patients [1].

\section{The present situation of medical education in China}

Since the founding of New China, under the correct leadership of the Party Central Committee and the concerted efforts of the people, China's medical education has made vigorous development, trained a large number of excellent talents with high-quality, and initially formed a medical education system with multi-levels, multi-specifications. The scientific and technological innovation ability of medical science research in various universities has been significantly enhanced, and medical education and international cooperation and exchange have gradually become more extensive and in-depth. Although China's medical education has achieved excellent results, with the continuous deepening of China's medical undertakings and medical education reforms, as well as the growing demands of the people for health services, there are still many problems in China's medical education. These problems are mainly reflected in: 1. The quality of medical education needs to be further improved. Medical education concepts, talent training 
models, teaching content, curriculum systems and teaching methods are not suitable for the development of modern medicine; 2 . The structure of medical education needs to be optimized. The major setting of various disciplines, the structure of talent training and the level of running schools cannot meet the requirements for establishing a new type of health service model. The cultivation of health talents cannot fully meet the development needs of grass-root medical and health services in rural areas and communities. The phenomenon that there is job but no one to take and there is no job to take exists at the same time.

\section{The problem of medical education in China}

Problems of the management system of medical education after merger. In recent years, China has carried out a reform of higher education system with the integration of medical colleges and comprehensive universities as an important content. System reform of higher education further promotes the development of higher education. This creates conditions for medical education to take full advantage of the deep natural sciences and humanities and social sciences of comprehensive universities or multidisciplinary universities. New training model of high-level medical talents is being gradually established, and the advantages of the joint school are gradually reflected. Due to the lack of mature experience and deep understanding, as well as the inaccurate positioning of management mode, the particularity of medical education and the status and role of medical school in medical education are not fully reflected. 2. Problems of the expansion of enrollment and insufficient investment in teaching. Since the founding of New China, China's medical education has initially established a continuous medical education system including basic education, post-graduate education and continuing education. The scale, level, quality and benefit of medical education have been improved to different degrees. The expansion of enrollment in colleges and universities has alleviated the pressure of employment and students' entrance to higher education, and has also brought problems to higher education. The influence of enrollment expansion and inadequate teaching investment on the quality of medical education is bound to arouse our guard. 3. Problems of the adapting degree of medical education system reform and the development of science and technology and the changes in social needs. In order to adapt to the constant changes in economic development and social needs, the medical education system and degree reform run through the whole process of medical education development. 4. Problems of the influence of the implementation of relevant health regulations on the cultivation of clinical ability of medical students. The promulgation of laws and regulations will play a positive and effective role in strengthening the construction of medical system and macro-administrative management and protecting the legitimate rights and interests of patients and medical personnel. However, these regulations to a certain extent limit the medical activities of doctors in the clinical field, reduce the number of clinical diseases and the opportunities of clinical practice and operation for medical students. Besides, they also affect the cultivation of clinical skills of medical students. How to reform clinical teaching means and methods is the challenge we face [2]. The challenges are: 1. The impact of higher education internationalization on medical education. It includes the internationalization of education resources, education system, talent training objectives, talent training standards, teaching management systems and operational mechanisms. 2. The impact of the National Tenth Five-Year Development Strategy on medical education. The National "Tenth Five-Year" Development Strategy has clearly defined that life science should be treated as a priority and key area of development. The adjustment of the national industrial structure and the general trend of national economic development put the life sciences in a very important position, and medicine is the main research and service field of life sciences. Therefore, many important issues have been raised on the positioning, scope, structure and talent cultivation of medical education. 3. The impact of modern science and technology development on medical education. The depth, breadth, degree of intersection and degree of transformation of modern science and technology have reached an unprecedented level. This puts a more urgent task on what kind of knowledge platform we build for our students. Medical education is a prominent field of lifelong learning and lifelong education. In this sense, what kind of knowledge platform constructed for modern medical education presents an urgent problem that needs us to think about. 4. From the perspective of the development of the health system and the health model, new demands are also placed on our medical education such as the concept of a five-star doctor mentioned by the World Health Organization. 5. The leap-forward development of higher medical education has put forward new requirements for medical education. With the expansion of enrollment, high-quality talent is an important issue of social concern. Is the positioning of medical education in a comprehensive university accurate? After entering a comprehensive university, can medical college complement each other and share resources? Has it created greater development space and conditions in teaching and research? These are all new requirements for medical education brought forward by leap-forward development [3].

\section{Decision and method for improving medical education in China}

Establishing and perfecting the system of "advance and retreat", mainly setting up elimination mechanism during the school period; 2. Following the example of Britain and America and trying to establish and improve general medicine; 3. Strengthening international exchanges and cooperation and accelerating the process of internationalization. This is the ultimate way to improve the quality of medical education and the status of medical education in China. It is necessary to continuously improve the quality of teaching and academic level, and 
actively participate in international affairs, and strive to make our medical degrees equal to and recognized by those of most developed countries. China's medical education should also face modernization, the world as well as the future. Standing at the new historical starting point, China's higher medical education will regard improving quality as the core task of reform and development. We will pay more attention to the strategic transformation of the development concept, pay more attention to training model innovation and institutional reform, and pay more attention to the system construction of quality assurance assessment. In addition, we will speed up the pace of building world-class medical colleges and universities with broader vision, more open attitude and more persistent efforts [4].

In short, China's medical education is at a stage of development. Faced with these challenges and opportunities, we need to put great energy to improve the level of medical education in China.

\section{References}

1. Xiong Xiangtao. Analysis of Current Situation and Development of Medical Education and Its Management System in China [J]. Chinese Journal of Social Medicine, 2017, (6): 541-544.

2. Chen Lu, Xiao Shuiyuan, Sun Zhenqiu. Analysis of New Problems and Countermeasures in Medical Education in China [J]. China Journal of Modern Medicine, 2006, (17): 2710-2713.

3. Lin Huiqing. The Challenge and Opportunity Facing the Instruction Reformation of the Higher Learning in Our Country in the New Age [J]. Chinese Journal of Medical Education Research, 2002, (1): $2-4,8$.

4. Wang Xiaohong, Huo Jiangtao, Mi Ning, etc. Problems and Solutions of Medical Education in China [J]. Digital User, 2013, (27): 172-172. 